\title{
The effect of hydrotropes on the solubility and mass transfer coefficient of 2-nitrobenzoic acid
}

\author{
S. Thenesh-Kumar ${ }^{1}$, D. Gnana-Prakash ${ }^{2}$, N. Nagendra-Gandhi ${ }^{3}$ \\ 1,2 St. Peter's Engineering College, Department of Chemical Engineering, Chennai - 600 054, India. \\ 3 A. C. College of Technology, Anna University, Department of Chemical Engineering, Chennai - 600 025, India, \\ e-mail: n_nagendra2002@yahoo.com
}

\begin{abstract}
A comprehensive investigation on the solubility and mass transfer coefficient enhancement of 2-nitrobenzoic acid through hydrotropy, has been undertaken. The solubility and mass transfer coefficient studies were carried out using hydrotropes such as sodium acetate, citric acid and nicotinamide under a wide range of hydrotrope concentrations ( 0 to $3.0 \mathrm{~mol} / \mathrm{L}$ ) and different system temperatures ( 303 to $333 \mathrm{~K}$ ). It was found that the solubility and mass transfer coefficient of 2-nitrobenzoic acid increases with an increase in hydrotrope concentration and also with system temperature. All hydrotropes used in this work showed an enhancement in the solubility and mass transfer coefficient to different degrees. The maximum enhancement factor value has been determined for both the solubility and mass transfer coefficient. The effectiveness of hydrotropes was measured in terms of Setschnew constant $K_{s}$ and reported for all the hydrotropes used in this study.
\end{abstract}

Keywords: hydrotropy, solubilization, mass transfer coefficient, separation.

\section{INTRODUCTION}

Hydrotropy is a unique and unprecedented solubilization technique in which certain chemical compounds termed as hydrotropes can be used to affect a several fold increase in the solubility of sparingly soluble solutes under normal conditions $\mathbf{1}^{\mathbf{1}}$. This increase in solubility in water is probably due to the formation of organized assemblies of hydrotrope molecules at critical concentrations ${ }^{2,3}$.

Hydrotropes in general are water-soluble and surfaceactive compounds that can significantly enhance the solubility of organic solutes such as esters, acids, alcohols, aldehydes, ketones, hydrocarbons, and fats ${ }^{4-9}$. The solubility enhancement in the organic compounds could be due to the formation of molecular structures in the form of complexes ${ }^{10-12}$.

Easy recovery of the dissolved solute and the possible reuse of hydrotrope solutions make this one the most attractive one, particularly at industrial levels. Besides the advantage of certain properties, such as the solvent character being independent of $\mathrm{pH}$, non-flammability, easy availability of hydrotropes, inexpensive aqueous phase makes this method superior to other solubilization methods ${ }^{13-18}$. Hydrotropy is a process which goes beyond other conventional solubilization methods such as miscibility, co-solvency, salting-in etc., since it offers high selectivity and unprecedented increase in solubility and mass transfer coefficient. The problem of emulsification, which is normally encountered with surfactant solution ${ }^{19}$, is not found with the hydrotrope solution. The effect of hydrotropes on the solubility and mass transfer coefficient for a series of organic esters, such as butyl acetate, ethyl benzoate, amyl acetate, methyl salicylate and benzyl acetate was studied in our earlier publications ${ }^{20-25}$. It has been observed that in many two-phase reaction systems involving a sparingly soluble organic compound like 2-nitrobenzoic acid, the mass transfer coefficient was found to be very low, solely due to the poor solubility of 2 -nitrobenzoic acid in the aqueous phase. Since 2-nitrobenzoic acid serves as raw material/intermediate for a wide variety of chemicals and allied products ${ }^{26-28}$ and the separation of 2-nitrobenzoic acid from any liquid mixture seems to be difficult, this hydrotropic technique can be adapted to increase the solubility as well as to separate such mixtures effectively. Data on various aspects of hydrotropic study on the solubility and mass transfer coefficient for the 2-nitrobenzoic acid-water system, have been reported for the first time.

\section{EXPERIMENTAL}

All the chemicals used in this work were procured from S D Fine-Chem Ltd, Mumbai with a manufacturer's stated purity of $99 \%$.

The experimental setup for the determination of solubility values consisted of a thermostatic bath and a separating funnel. For each solubility test, an excess amount of powdered solid was taken in a separating funnel and $100 \mathrm{ml}$ of a solution of the hydrotrope of known concentration was added. The separating funnel was immersed in a constant-temperature bath fitted with a temperature controller which could control the temperature within $\pm 0.1^{\circ} \mathrm{C}$. The setup was kept overnight for equilibration. After equilibrium was attained, the solution was filtered from the remaining solid. The concentration of the dissolved organic acid in aqueous hydrotrope solutions was analyzed by titration using standardized $\mathrm{NaOH}$ solutions exploiting phenolphthalein as an indicator. All the solubility experiments were conducted in a duplicate to check the reproducibility. The observed error in the reproducibility was $<2 \%$.

The experimental setup for the determination of the mass transfer coefficient consisted of a vessel provided with baffles and a turbine impeller run by a motor to agitate the mixture. The vessel used for mass transfer studies is of the $40 \mathrm{~cm}$ height and the $15 \mathrm{~cm}$ inner diameter. The turbine impeller diameter is $5 \mathrm{~cm}$, the width is $1 \mathrm{~cm}$, and the length is $1.2 \mathrm{~cm}$. It has four blades. The baffle is $40 \mathrm{~cm}$ high with a diameter of $1.5 \mathrm{~cm}$. There are about four baffles that rotate at a speed of $600 \mathrm{rpm}$.

For each run, to measure the mass transfer coefficient, an excess amount of powdered solid was added to the 
aqueous solution of the hydrotrope of known concentration. The sample was then agitated for a known time of 600, 1200, 1800 and 2400 seconds. After the end of the fixed time $t$, the entire mixture was transferred to a separating funnel. After allowing the sample to stand for some time, the solution was filtered from the remaining solid. The concentration of the solubilized organic acid in aqueous hydrotrope solutions at time $t$ was analyzed in the same way as for the solubility determinations. A plot of $-\log \left[1-C_{b} / C^{*}\right]$ versus $t$ is drawn, where $C_{b}$ is the concentration of 2-nitrobenzoic acid at time $t$ and $C^{*}$ is the equilibrium solubility of 2-nitrobenzoic acid at the same hydrotrope concentration. The slope of the graph gives $k_{L} a / 2.303$, from which $k_{L} a$, the mass transfer coefficient was determined. Duplicate runs were made to check the reproducibility. The observed error was $<2 \%$.

\section{RESULTS AND DISCUSSION}

\section{Solubility}

The solubility of 2-nitrobenzoic acid standard in water is $4.20 \times 10^{-2} \mathrm{~mol} / \mathrm{L}$ at $303 \mathrm{~K}$, compared to $4.20 \times 10^{-2} \mathrm{~mol} /$ $\mathrm{L}$ as reported by Dean (1987). Thus, the solubility values in water are in excellent agreement with the earlier reported values ${ }^{\mathbf{2 9}, \mathbf{3 0}}$.

The experimental data, representing the average of duplicate determinations on the effect of hydrotropes, i.e., sodium acetate, citric acid and nicotinamide on the solubility of 2-nitrobenzoic acid are plotted in Figures $1-3$. Sodium acetate is one of the hydrotropes used in this study. The solubility of 2-nitrobenzoic acid in water at $303 \mathrm{~K}$ in the absence of any hydrotrope is $4.20 \times 10^{-2} \mathrm{~mol} /$ L (Figure 1). It has been observed that the solubility of 2nitrobenzoic acid in water increases significantly only after the addition of $0.30 \mathrm{~mol} / \mathrm{L}$ of sodium acetate in the aqueous solution. This concentration is referred to as the Minimum Hydrotrope Concentration (MHC) ${ }^{\mathbf{3 1}}$.

Therefore, it is evident that hydrotropic solubilization is displayed only above the MHC, irrespective of the system temperature. This MHC value assumes greater significance in the context of hydrotrope solutions recovery. Since hydrotropy appears to operate only at significant concentrations of hydrotrope in water, most hydrotropic solutions release the dissolved 2-nitrobenzoic acid on dilution with water below MHC. The knowledge of MHC values is necessary, especially at industrial levels, as it ensures ready recovery of the hydrotrope for reuse. The $\mathrm{MHC}$ values remained unaltered, even at increased system temperatures.

The solubilization effect varies with the concentration of hydrotrope (Figure 1). In the present case, a clear increasing trend in the solubility of 2-nitrobenzoic acid was observed above the MHC of sodium acetate. This increasing trend is maintained only up to a certain concentration of sodium acetate in the aqueous solution, beyond which there is no appreciable increase in the solubility of 2-nitrobenzoic acid. This concentration of sodium acetate (hydrotrope) in the aqueous solution is referred to as the maximum hydrotrope concentration $\left(C_{\max }\right)$. From the analysis of the experimental data, it is observed that further increase in hydrotrope concentration beyond $C_{\max }$ does not bring any appreciable increase

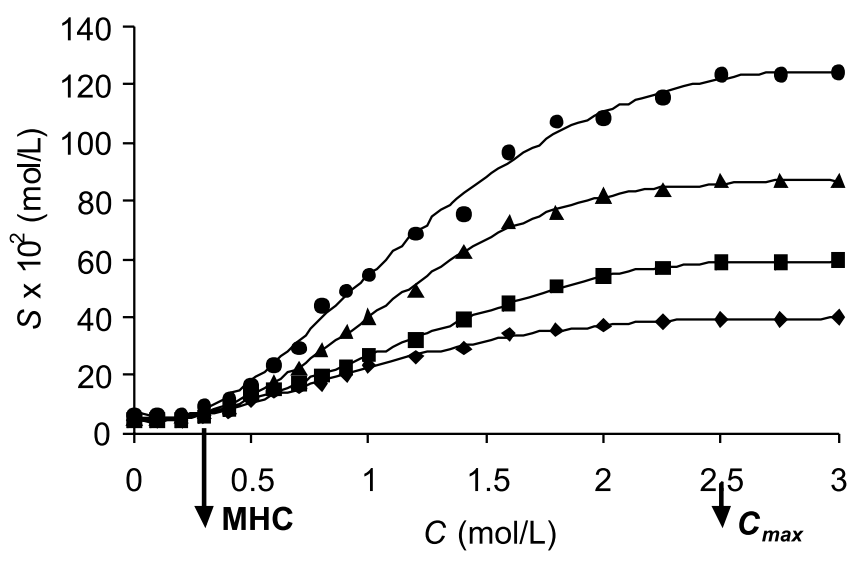

Figure 1. The effect of Sodium acetate concentration (C) on the solubility (S) of 2-nitrobenzoic acid in water at different temperatures $\mathrm{T}=303 \mathrm{~K}(\diamond), 313 \mathrm{~K}(\boldsymbol{\bullet})$, $323 \mathrm{~K}(\boldsymbol{\Delta})$ and $333 \mathrm{~K}(\bullet)$.

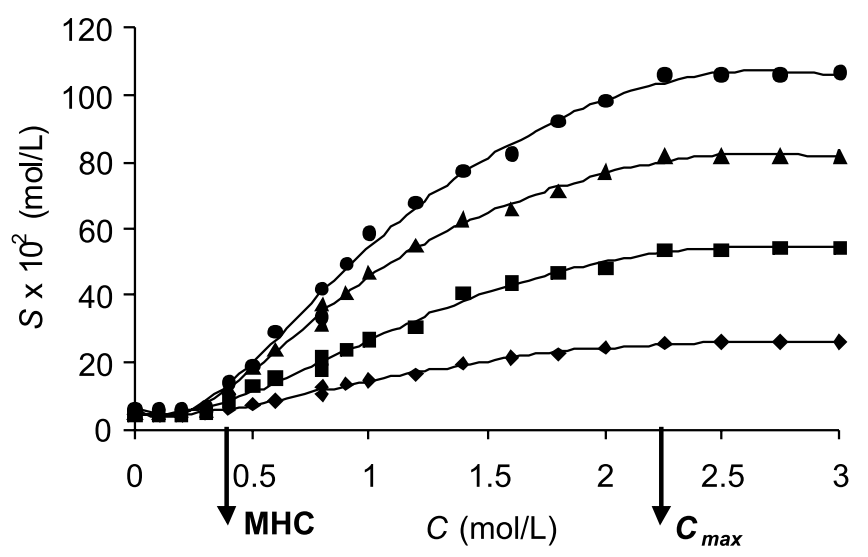

Figure 2. The effect of Citric acid concentration (C) on the solubility (S) of 2-nitrobenzoic acid in water at different temperatures $\mathrm{T}=303 \mathrm{~K}(\diamond), 313 \mathrm{~K}(\mathbf{\bullet})$, 323K (४ $)$ and $333 \mathrm{~K}(\bullet)$.

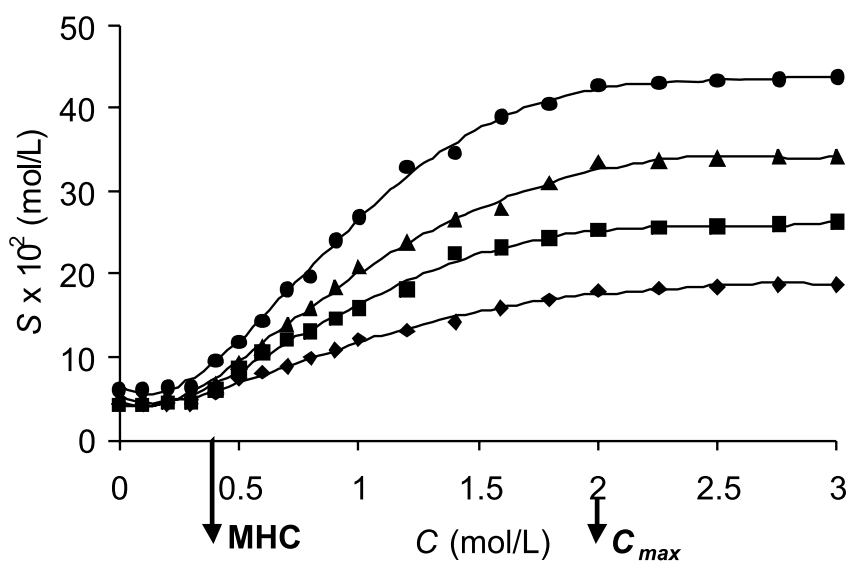

Figure 3. The effect of Nicotinamide concentration (C) on the solubility $(\mathrm{S})$ of 2-nitrobenzoic acid in water at different temperatures $\mathrm{T}=303 \mathrm{~K}(\bullet), 313 \mathrm{~K}(\boldsymbol{\bullet})$, 323K ( $\mathbf{\Delta})$ and $333 \mathrm{~K}(\bullet)$.

in the solubility of 2-nitrobenzoic acid even up to 3.00 $\mathrm{mol} / \mathrm{L}$ of sodium acetate in the aqueous solution.

The saturation of the hydrotropic effect beyond $C_{\max }$ may, due to the non-availability of water molecules, form further aggregates comprising of additional $\mathrm{MHC}$ agglomerates. Similar to the MHC values, the $C_{\max }$ values of hydrotropes also remained unaltered at increased system temperatures. The knowledge of the $\mathrm{MHC}$ and $C_{\max }$ values 
of each hydrotrope with respect to a particular solute assumes greater significance in this study since it indicates the beginning and saturation of the solubilization effect of hydrotropes. The values of MHC and $C_{\max }$ of a hydrotrope with respect to 2-nitrobenzoic acid may be useful in determining the recovery of the dissolved 2-nitrobenzoic acid, even to an extent of the calculated amount from hydrotrope solutions at any concentration between MHC and $C_{\max }$ by simple dilution with distilled water. This is the unique advantage of the hydrotropic solubilization technique.

From the experimental data plotted in Figure 1, it can further be observed that, in order to achieve the particular solubility of 2-nitrobenzoic acid, say $23 \times 10^{-2} \mathrm{~mol} / \mathrm{L}$, the sodium acetate concentration should be $1.00 \mathrm{~mol} / \mathrm{L}$ at $303 \mathrm{~K}, 0.90 \mathrm{~mol} / \mathrm{L}$ at $313 \mathrm{~K}, 0.70 \mathrm{~mol} / \mathrm{L}$ at $323 \mathrm{~K}$ and $0.60 \mathrm{~mol} / \mathrm{L}$ at $333 \mathrm{~K}$ in the aqueous solution. Thus it can be seen that as the system temperature increases, the concentration of sodium acetate required in the aqueous phase to achieve a particular solubility of 2-nitrobenzoic acid decreases. A similar trend has been observed for other systems, too. It has also been observed that the solubilization effect of sodium acetate was not a linear function of the concentration of the sodium acetate. The solubilization effect of sodium acetate increases with increase in hydrotrope concentration and also with system temperature ${ }^{32}$.

A similar trend has been observed in the solubilization effect of other hydrotropes, namely citric acid and nicotinamide. It has also been observed that the MHC values of hydrotrope used in this work range between 0.30 and $0.40 \mathrm{~mol} / \mathrm{L}$ (Table 1) and the $C_{\max }$ values of hydrotropes range between 2.00 and $2.50 \mathrm{~mol} / \mathrm{L}$ (Table 1). The highest value of solubilization enhancement factors $\varphi_{\mathrm{s}}$, which is the ratio of solubility values in the presence and absence of a hydrotrope, has been observed in the case of sodium acetate as 20.12 at a system temperature of $333 \mathrm{~K}$ (Table 2).

\section{Mass Transfer Coefficient}

The mass transfer coefficient of 2-nitrobenzoic acid + water system in the absence of any hydrotrope was determined as $1.20 \times 10^{-3} \mathrm{~s}^{-1}$ at $303 \mathrm{~K}$ (Table 3). The effect of different hydrotropes on the mass transfer coefficient of 2nitrobenzoic acid at different hydrotrope concentrations is also given in the same table. It can be seen that a

Table 1. The MHC and $C_{\max }$ values for Hydrotropes

\begin{tabular}{|l|c|c|}
\hline Hydrotrope & $\mathrm{MHC}(\mathrm{mol} / \mathrm{L})$ & $C_{\max }(\mathrm{mol} / \mathrm{L})$ \\
\hline Sodium acetate & 0.30 & 2.50 \\
\hline Citric acid & 0.40 & 2.25 \\
\hline Nicotinamide & 0.40 & 2.00 \\
\hline
\end{tabular}

Table 2. The maximum solubilization enhancement factor $\left(\varphi_{\mathrm{s}}\right)$ of 2-nitrobenzoic acid

\begin{tabular}{|l|c|c|c|c|}
\hline \multirow{2}{*}{ Hydrotrope } & \multicolumn{4}{|c|}{ Maximum enhancement factor for solubility } \\
& $\begin{array}{c}\mathrm{T}=303 \\
\mathrm{~K}\end{array}$ & $\begin{array}{c}\mathrm{T}=313 \\
\mathrm{~K}\end{array}$ & $\begin{array}{c}\mathrm{T}=323 \\
\mathrm{~K}\end{array}$ & $\begin{array}{c}\mathrm{T}=323 \\
\mathrm{~K}\end{array}$ \\
\hline $\begin{array}{l}\text { Sodium } \\
\text { acetate }\end{array}$ & 9.42 & 13.50 & 17.41 & 20.12 \\
\hline Citric acid & 6.22 & 12.30 & 16.37 & 17.23 \\
\hline Nicotinamide & 4.48 & 5.98 & 6.86 & 7.13 \\
\hline
\end{tabular}

Table 3. The effect of hydrotrope concentration $(C)$ on the mass transfer coefficient $\left(k_{L a}\right)$ of 2-nitrobenzoic acid

\begin{tabular}{|c|c|c|c|}
\hline Hydrotrope & $\begin{array}{c}C \\
(\mathrm{~mol} / \mathrm{L})\end{array}$ & $\begin{array}{c}k_{L a} \\
10^{3}\left(\mathrm{~s}^{-1}\right)\end{array}$ & $\begin{array}{c}\text { Enhancement factor } \\
\text { for mass transfer } \\
\text { coefficient }\left(\varphi_{\mathrm{mtc}}\right)\end{array}$ \\
\hline \multirow{16}{*}{$\begin{array}{l}\text { Sodium } \\
\text { acetate }\end{array}$} & 0.00 & 1.20 & - \\
\hline & 0.20 & 1.30 & 1.08 \\
\hline & $0.30(\mathrm{MHC})$ & 1.80 & 1.49 \\
\hline & 0.40 & 1.87 & 1.55 \\
\hline & 0.60 & 2.78 & 2.31 \\
\hline & 0.80 & 3.79 & 3.17 \\
\hline & 1.00 & 4.81 & 4.00 \\
\hline & 1.20 & 5.97 & 4.96 \\
\hline & 1.40 & 7.21 & 6.00 \\
\hline & 1.60 & 7.67 & 6.40 \\
\hline & 1.80 & 8.53 & 7.10 \\
\hline & 2.00 & 8.96 & 7.45 \\
\hline & 2.25 & 9.29 & 7.72 \\
\hline & $2.50\left(C_{\max }\right)$ & 11.43 & 9.50 \\
\hline & 2.75 & 11.50 & 9.58 \\
\hline & 3.00 & 12.00 & 10.01 \\
\hline \multirow{15}{*}{ Citric acid } & 0.00 & 1.20 & - \\
\hline & 0.20 & 1.24 & 1.03 \\
\hline & $0.40(\mathrm{MHC})$ & 1.34 & 1.11 \\
\hline & 0.60 & 2.60 & 2.16 \\
\hline & 0.80 & 2.90 & 2.41 \\
\hline & 1.00 & 4.20 & 3.49 \\
\hline & 1.20 & 5.00 & 4.16 \\
\hline & 1.40 & 6.15 & 5.11 \\
\hline & 1.60 & 7.14 & 5.93 \\
\hline & 1.80 & 7.67 & 6.37 \\
\hline & 2.00 & 8.43 & 7.01 \\
\hline & $2.25\left(C_{\max }\right)$ & 9.20 & 7.65 \\
\hline & 2.50 & 9.28 & 7.71 \\
\hline & 2.75 & 9.38 & 7.80 \\
\hline & 3.00 & 9.48 & 7.88 \\
\hline \multirow{15}{*}{ Nicotinamide } & 0.00 & 1.20 & - \\
\hline & 0.20 & 1.22 & 1.01 \\
\hline & $0.40(\mathrm{MHC})$ & 1.30 & 1.07 \\
\hline & 0.60 & 2.43 & 2.02 \\
\hline & 0.80 & 2.55 & 2.12 \\
\hline & 1.00 & 3.73 & 3.10 \\
\hline & 1.20 & 4.14 & 3.44 \\
\hline & 1.40 & 4.84 & 4.02 \\
\hline & 1.60 & 5.23 & 4.35 \\
\hline & 1.80 & 5.80 & 4.80 \\
\hline & $2.00\left(C_{\max }\right)$ & 8.28 & 6.88 \\
\hline & 2.25 & 8.33 & 6.92 \\
\hline & 2.50 & 8.42 & 6.99 \\
\hline & 2.75 & 8.57 & 7.12 \\
\hline & 3.00 & 8.69 & 7.22 \\
\hline
\end{tabular}

threshold value of $0.30 \mathrm{~mol} / \mathrm{L}$ is required to effect significant enhancement in the mass transfer coefficient of 2nitrobenzoic acid + water system, as observed in the case of solubility determinations. The mass transfer coefficient of 2-nitrobenzoic acid + water system increases with the rise in sodium acetate concentration. The maximum enhancement factor for mass transfer coefficient of 2nitrobenzoic acid + water system in the presence of sodium acetate was found to be 9.50 (Table 3). A similar trend in the mass transfer coefficient enhancement $\left(\varphi_{\text {mtc }}\right)$ of 2-nitrobenzoic acid has been observed for other hydrotropes also, namely citric acid and nicotinamide. 
The highest value of $\varphi_{\mathrm{mtc}}(9.50)$ has been observed in the presence of sodium acetate as hydrotrope at $C_{\max }$ of 2.50 $\mathrm{mol} / \mathrm{L}$.

Table 4. Setschenow constant $\left(K_{s}\right)$ of hydrotropes with respect to 2-nitrobenzoic acid

\begin{tabular}{|l|c|c|c|c|}
\hline \multirow{2}{*}{ Hydrotrope } & \multicolumn{4}{|c|}{ Setschenow constant $\left(K_{s}\right)$} \\
\cline { 2 - 5 } & $\begin{array}{c}\mathrm{T}=303 \\
\mathrm{~K}\end{array}$ & $\begin{array}{c}\mathrm{T}=313 \\
\mathrm{~K}\end{array}$ & $\begin{array}{c}\mathrm{T}=323 \\
\mathrm{~K}\end{array}$ & $\begin{array}{c}\mathrm{T}=333 \\
\mathrm{~K}\end{array}$ \\
\hline $\begin{array}{l}\text { Sodium } \\
\text { acetate }\end{array}$ & 0.384 & 0.453 & 0.492 & 0.519 \\
\hline Citric acid & 0.343 & 0.440 & 0.450 & 0.470 \\
\hline Nicotinamide & 0.321 & 0.388 & 0.437 & 0.404 \\
\hline
\end{tabular}

\section{Effectiveness of Hydrotropes}

The effectiveness factor of each hydrotrope with respect to 2-nitrobenzoic acid at different system temperatures has been determined by analyzing the experimental solubility data for each case applying the model suggested by Setschenow (1951) and later modified by Pathak and Gaikar (1992), as given by the equation

$\log \left[S / S_{\mathrm{m}}\right]=K \mathrm{~s}\left[C_{\mathrm{s}}-C_{\mathrm{m}}\right]$

Where $S$ and $S_{\mathrm{m}}$ are the solubility of 2-nitrobenzoic acid at any hydrotrope concentration $C_{\mathrm{s}}$ and the minimum hydrotrope concentration $C_{\mathrm{m}}$, respectively. The Setschenow constant $K_{\mathrm{s}}$ can be considered as a measure of the effectiveness of a hydrotrope at any given conditions of hydrotrope concentration and system temperature. The Setschenow constant values of hydrotropes, namely sodium acetate, citric acid and nicotinamide for 2nitrobenzoic acid + water system at different system temperatures are listed in Table 4. The highest value has been observed as 0.519 in the case of sodium acetate as hydrotrope at $333 \mathrm{~K}$.

\section{CONCLUSIONS}

The solubility of 2-nitrobenzoic acid, which is practically insoluble in water, has been increased to a maximum of 20.12 times in the presence of sodium acetate as hydrotrope with a corresponding increase in the mass transfer coefficient. This would be useful in increasing the rate of the output of the desired product made from 2-nitrobenzoic acid. The recovery of the dissolved 2nitrobenzoic acid from hydrotrope solution is ensured at any hydrotrope concentration between $\mathrm{MHC}$ and $C_{\max }$ by simple dilution with distilled water, which alters the solution properties of hydrotrope aggregates instantaneously affecting the MHC agglomerates. This also facilitates the reuse of hydrotrope solution, which will eliminate the huge cost and energy normally involved in the separation of the solubilized 2-nitrobenzoic acid from its solution. The unprecedented increase in the solubilizing effect of hydrotropes is attributed to the formation of organized aggregates of hydrotrope molecules at a particular concentration.

\section{LITERATURE CITED}

1. Neuberg, C. (1916). Hydrotropy. Biochem. Z. 76, 107 108.

2. Badwan, A.A., Khordagui L.K.E. \& Salesh A. M. (1982). The Solubility of Benzodiazepines in Sodium Salicylate So- lutions and a Proposed Mechanism for Hydrotropic Solubilization. Int. J. Pharm. 13, 67 - 74.

3. Balasubramanian, D., Srinivas V., Gaikar V. G. \& Sharma M. M. (1989). Aggregation Behaviour of Hydrotropic Compounds in Aqueous Solutions. J. Phys. Chem. 93, $3865-3870$.

4. Friberg, S. E. \& Brancewicz C. (1994). O/W Microemulsions and Hydrotropes: The Coupling Action of a Hydrotrope. Langmuir. 10, 2945 - 2949.

5. Raynaud-Lacroze, P.O. \& Tavare N. S. (1993). Separation of 2-naphthol: Hydrotropy and Precipitation. Ind. Eng. Chem. Res. 32, $685-691$.

6. Laxman, M. \& Sharma M. (1990). Reduction of Isophorone with Borohydride: Change in Regio Selectivity with Hydrotropes. Synth. Commun. 20, $111-117$.

7. Maheswari, R.K. (2006). Novel application of hydrotopic solubilization in the analysis of bulk sample of ketoprofen and salicylic acid. Asian J. Chem. 18, 393 - 396.

8. Gaikar, V.G. \& Phatak P.V. (1993). Solubility o- and pChlorobenzoic Acid in Hydrotrope Solutions. J. Chem. Eng. Data. 38, 217 - 220.

9. Colonia, E.J., Dixit A.B. \& Tavare N.S. (1998). Phase Relations of o- and p- Chlorobenzoic Acids in Hydrotrope Solutions. J. Chem. Eng. Data. 43, $220-225$.

10. Hodgdon, T.K. \& Kaler E.W. (2007). Hydrotropic solutions. Curr Opin Colloid Interface Sci. 12, 121 - 128.

11. Ooya, T., Huh K.M., Saitoh M., Tamiya E. \& Park K. (2005). Self-assembly of cholesterol-hydrotropic dendrimer conjugates into micelle-like structure: Preparation and hydrotropic solubilization of paclitaxel. Sci Technol Adv Mater. $6,452-456$.

12. Rovetto, L.J., Strobel T.A., Koh C.A. \& Sloan Jr.E.D. (2006). Is gas hydrate formation thermodynamically promoted by hydrotrope molecules? Fluid Phase Equilib. 247, 84 -89 .

13. Agarwal, M. \& Gaikar V. G. (1992). Extractive Separation Using Hydrotropes. Sep. Technol. 2, 79 - 84.

14. Gaikar, V.G. \& Sharma M.M. (1986). Extractive Separation with Hydrotropes. Solvent Extr. Ion Exch. 4, 839 - 846.

15. Mahapatra, A., Gaikar V.G. \& Sharma M.M. (1988). New Strategies in Extractive Distillation; Use of Aqueous Solution of Hydrotropes and Organic Bases as Solvent for Organic Acids. Sep. Sci. Technol. 23, 429 - 436.

16. Agarwal, M. \& Gaikar V.G. (1992). Extractive distillation with aqueous solutions of hydrotropes, Chem. Eng. Commun. 115, 83 - 94.

17. Friberg, S.E., Yang J. \& Huang T. (1996). Reversible Extraction Process of Phenyl Ethyl Alcohol, a Fragrance. Ind. Eng. Chem. Res. 35, 2856 - 2859.

18. Gaikar, V.G. \& Phatak P.V. (1999). Selective Solubilisation of Isomers in Hydrotrope Solution o-/p-Chlorobenzoic acids and o-/p-Nitro anilines. Sep. Sci. Technol. 34, 439-459.

19. Hefa C. \& David S. (2007). Separation of organic compounds from surfactant solution: A Review. Sep. Sci. Technol. 42, 453 - 475.

20. Nagendra-Gandhi, N., Dharmendira-Kumar M. \& Sathyamurthy N. (1998). Effect of Hydrotropes on Solubility and Mass-Transfer Coefficient of Butyl Acetate. J. Chem. Eng. Data. 43, 695 - 699.

21. Nagendra-Gandhi, N., Dharmendira-Kumar M. \& Sathyamurthy N. (1998). Solubility and Mass Transfer Coefficient Enhancement of Ethyl Benzoate through Hydrotropy. Hungarian J. Ind. Chem. 26, 63 - 68.

22. Nagendra-Gandhi, N. \& Dharmendira-Kumar M. (2000). Effect of Hydrotropes on Solubility and Mass Transfer Coefficient of Amyl Acetate. Bioprocess Eng. 23, 31 - 36.

23. Nagendra-Gandhi, N. \& Dharmendira-Kumar, M. (2000). Effect of Hydrotropes on Solubility and Mass Transfer Coefficient of Methyl Salicylate. J. Chem. Eng. Data, 45, $419-423$. 
24. Meyyappan N. \& Nagendra-Gandhi, N. (2004). Solubility and Mass Transfer Coefficient Enhancement of Benzyl Acetate in Water through Hydrotropy. J. Chem. Eng. Data. 49, $1290-1294$.

25. Meyyappan, N. \& Nagendra Gandhi N. (2005). Solubility and Mass Transfer Coefficient Enhancement of Benzyl Benzoate in Water through Hydrotropy. J. Chem. Eng. Data. $50,796-800$.

26. Agrawal, S., Pancholi S.S., Jain N.K. \& Agrawal G.P. (2004). Hydrotropic Solubilization of nimesulide for parenteral administration, Int. J. Pharm. 274, 149 - 155.

27. Nicoli, S., Zani F., Bilzi S., Bettini R. \& Santi P. (2008). Association of nicotinamide with parabens: Effect on solubility, partition and transdermal permeation. Eur J Pharm Biopharm. 69, 613 - 621.

28. Dandekar, D.V., Jayaprakasha G.K. \& Patil B.S. (2008). Hydrotropic extraction of bioactive limonin from sour orange (Citrus aurantium L.) seeds, Food Chem. 109, 515 520 .

29. John, A.D. (1987). Lange's Handbook of Chemistry (13 ${ }^{\text {th }}$ ed.). New York: McGraw-Hill

30. Perry, R.H. (1997). Perry's Chemical Engineer's Handbook ( $7^{\text {th }}$ ed.). New York: McGraw-Hill.

31. Miguel, G.N., Carla C.S., Katia R.P. \& Beatriz E.G. (2007). The photophysical determination of the minimum hydrotrope concentration of aromatic hydrotropes. J. Colloid and Interface Sci. 315, 810 - 813.

32. Wagle, V.B, Kothari P.S \& Gaikar V.G. (2007). Effect of temperature on aggregation behaviour of aqueous solution of sodium cumene sulfonate. J. Mol Liq. 133, 68 - 76 . 